\title{
The trends in consumption patterns of toothbrushes and toothpastes in Lebanon
}

Mounir Doumit ${ }^{1}$ and Fida Al Sayah ${ }^{1}$

${ }^{1}$ Department of Dental Public Health Lebanese University School of Dentistry, Lebanese University, Beirut, Lebanon (Correspondence to: Mounir Doumit: mhdoumit@sodetel.net.lb).

\begin{abstract}
Background: The prevalence of dental cavities has been rising especially during the past ten years. Tooth brushing twice a day using a fluoridated toothpaste is a crucial preventive measure. The World Health Organization (WHO) has recommended the yearly use of 6 tubes of toothpaste of $170 \mathrm{~g}$ each and 4 toothbrushes per individual.

Aim: To evaluate the individual yearly consumption of toothpaste tubes and toothbrushes in Lebanon using the amount supplied to the market as a proxy measure after checking if the products meet the standards.

Methods: This study was based on performing secondary quantitative data analysis of the amount of supplied toothpastes and toothbrushes between 2000 and 2016 in Lebanon. The quality of toothpaste brands available in the market was evaluated by reviewing LIBNOR (Lebanese Standards Institution) guidelines that govern the quality and testing standards of oral health products in Lebanon.

Results: The yearly supply of toothpaste tubes per individual increased progressively from 1.27 tubes to 1.58 tubes between the year 2000 and 2016 respectively. The yearly supply of toothbrushes per individual fluctuated between 3.1 toothbrushes in 2000 and 3.24 toothbrushes in 2016, where the trend of supply reveals a plateau phase followed by steep increases and decreases between 2012 and 2016. Guidelines governing the quality of toothpastes are regulated by LIBNOR and follow European Standards.

Conclusion: The yearly consumption of both toothpaste tubes and toothbrushes was below WHO recommendations. This raises the necessity of increasing the promotion of the importance of proper oral hygiene practices as well as the distribution of tubes of toothpastes and toothbrushes to people in need.
\end{abstract}

Keywords: Toothpaste tubes, toothbrushes, supply, consumption, WHO recommendations

Citation: Doumit M; Al Sayah F. The trends in consumption patterns of toothbrushes and toothpastes in Lebanon. East Mediterr Health J. 2018;24(2):216-220. https://doi.org/10.26719/2018.24.2.216.

Received: 03/04/17; accepted: 30/01/18

Copyright (c) World Health Organization (WHO) 2018. Some rights reserved. This work is available under the CC BY-NC-SA 3.0 IGO license (https:// creativecommons.org/licenses/by-nc-sa/3.o/igo).

\section{Introduction}

Dental caries are the most common oral condition affecting both children and adults. Up to $90 \%$ of children and almost all adults suffer from dental caries (1). The prevalence of dental caries has been rising especially during the past ten years in both high and low-income countries. This has been specifically affecting those who are of low socio-economic status and are thus suffering the greatest burden of oral diseases $(2,3,4)$.

Caries during childhood can result in weight reduction, growth delay and consequently poorer quality of life (5). According to a report published by the World Health Organization (WHO), dental caries has been linked to several modifiable risk factors; of relevance to this study are poor oral hygiene practices (6). A preventive approach has been promoted by WHO to reduce the burden of dental caries and oral diseases and improve oral health; of significance to this study is promoting adequate fluoride intake and proper oral hygiene practices (6).

Tooth brushing at least once a day using fluoridated toothpaste resulted in less dental caries in children and adolescents where tooth brushing twice a day yielded even greater benefit (7). The use of affordable fluoridated toothpaste has been recognized and advised as a source of fluoride intake especially at low income countries and where national preventive oral health interventions are lacking (6).

Tooth brushing using a fluoridated toothpaste twice a day has been recommended for caries prevention and better control of plaque $(8,9)$. Alternatively, it is preferred to perform tooth brushing after meals to help remove food debris thus reducing the contact time between sucrose found in food debris and the enamel (8). In that respect, the WHO recommended a yearly consumption of four tooth brushes and 6 tubes of toothpastes per individual. This translates to using a new toothbrush every 3 months and one tube of toothpaste every two months (10). Studies conducted about oral hygiene practices in Lebanon have only tackled the frequency of tooth brushing and revealed that it does not comply with the international recommendations (11,12). No studies have been conducted to estimate and evaluate the 
supply of toothpaste tubes and toothbrushes and hence approximate the consumption of these products by the Lebanese population. In view of that, this study aims to evaluate one of the integral oral hygiene practices, namely tooth brushing among the Lebanese population through analyzing the yearly supply of toothpaste tubes and toothbrushes per individual between the year 2000 and 2016, and compare it to WHO consumption recommendations.

\section{Methods}

This study was based on performing secondary quantitative data analysis of the amount of supplied toothpaste tubes and brushes, and the review of standards governing the quality control of these products in the Lebanese market. According to the Lebanese Ministry of Industry in 2013, Lebanon does not produce local toothpaste and toothbrushes, thereby depending on imported items. The amount of imported toothpaste tubes and toothbrushes between the year 2000 and 2016 were retrieved from the Lebanese Customs registry (13).

The data provided by the Lebanese Customs reported the weight of toothpaste tubes and toothbrushes imported by tons. The average weight of a toothpaste tube and a toothbrush was estimated to be 170 grams and 20 grams respectively (the weight is estimated without including the toothpaste tube itself and the toothbrush packing). The estimates were calculated after performing a review of the items available at pharmacies. The average weight of a toothpaste tube and a toothbrush was used to calculate the total number of imported toothpaste tubes and toothbrushes. Consequently, the annual number of toothpaste tubes and toothbrushes supplied to every individual was calculated by dividing the total number of toothpaste tubes and toothbrushes imported by the total number of the Lebanese population, which is approximated to be 4 million $(9,14)$.

Furthermore, this study reviewed the guidelines that govern the quality and testing standards of oral health products in Lebanon. Imported toothpaste tubes and toothbrushes have to comply with certain standards that are regulated by the Lebanese Standards Institution (LIBNOR) which has adopted the "European Standards EN ISO" which regulate the guidelines for toothpaste requirements, testing methods and marking (15).

This study was only limited to secondary analysis where data were restricted to the number of imported toothbrushes and toothpaste tubes, and did not involve the inclusion of research participants or the use of data related to human subjects. Therefore, this study was exempted from an institutional review board approval.

\section{Results}

Results of the yearly supply of toothpaste tubes per individual between 2000 and 2016 fluctuated between 1.27 tubes in the year 2000 and 1.58 tubes in the year 2016 (Table 1). The supply of toothpaste tubes reveals a progressive modest increase between 2000 and 2016 (Figure 1). The yearly supply of toothbrushes per individual fluctuated between 3.1 toothbrushes in 2000 and 3.24 toothbrushes

\begin{tabular}{|c|c|c|c|c|}
\hline Year & $\begin{array}{l}\text { Quantity of toothpastes } \\
\text { (tons) }\end{array}$ & $\begin{array}{c}\text { Number of toothpaste } \\
\text { tubes/person }\end{array}$ & $\begin{array}{c}\text { Quantity of } \\
\text { Toothbrushes (ton) }\end{array}$ & $\begin{array}{l}\text { Number of toothbrushes/ } \\
\text { person }\end{array}$ \\
\hline 2000 & 866 & 1.27 & 248 & 3.1 \\
\hline 2001 & 894 & 1.31 & 163 & 2.0 \\
\hline 2002 & 1042 & 1.53 & 105 & 1.3 \\
\hline 2003 & 959 & 1.41 & 101 & 1.26 \\
\hline 2004 & 934 & 1.37 & 111 & 1.38 \\
\hline 2005 & 971 & 1.42 & 107 & 1.33 \\
\hline 2006 & 908 & 1.33 & 117 & 1.46 \\
\hline 2007 & 1277 & 1.87 & 92 & 1.15 \\
\hline 2008 & 1063 & 1.56 & 117 & 1.46 \\
\hline 2009 & 1113 & 1.63 & 114 & 1.42 \\
\hline 2010 & 1283 & 1.88 & 141 & 1.76 \\
\hline 2011 & 1160 & 1.7 & 161 & 2.0 \\
\hline 2012 & 1107 & 1.62 & 166 & 2.0 \\
\hline 2013 & 1310 & 1.92 & 341 & 4.2 \\
\hline 2014 & 1329 & 1.95 & 280 & 3.5 \\
\hline 2015 & 1212 & 1.78 & 186 & 2.33 \\
\hline 2016 & 1074 & 1.58 & 259 & 3.24 \\
\hline
\end{tabular}

One tube of toothpaste is estimated to weight $170 \mathrm{~g}$

Numbers shows estimates from weight not actual number of imported tubes of toothbrushes and toothpastes. 
in 2016, where the trend of supply reveals a steep decrease between 2000 and 2002 followed by a plateau and then steep increases and decreases between 2012 and 2016 (Figure 1). The average yearly supply over 17 years was estimated to be 1.6 toothpaste tubes and 2 toothbrushes per individual. The study reveals that products imported to Lebanon abide by LIBNOR guidelines.

\section{Discussion}

This study shows that the yearly supply of toothpaste tubes per individual in Lebanon has increased progressively from 1.27 in 2000 to 1.58 toothpaste tubes in 2016 with an average of 1.6 toothpaste tubes per individual, but is well below the WHO recommendation which is 6 tubes of toothpastes per year per individual (10).

However, our results show steep fluctuations in the supply of toothbrushes between 2010 and 2016 possibly because of irregularity of importation due to political instability in the country during this period. Although our yearly average supply of two toothbrushes per individual is well below WHO and American Dental Association (ADA) recommendations of 4 toothbrushes per year $(10,16)$, there has been an observed increase in the supply of toothbrushes that reached 3.24 toothbrushes per individual in 2016; thus, closing the gap with WHO and $\mathrm{ADA}$ recommendations.

The supply of toothpaste tubes and toothbrushes, which is below the recommended amount by WHO, reflects a deficiency in the yearly consumption of toothpaste tubes and brushes by the Lebanese population, which in turn may reflect poor oral hygiene practices. This correlates with an earlier study about oral hygiene practices in Lebanon which revealed that only $50 \%$ of females and $30 \%$ of males brush their teeth twice a day (11). Another study conducted in Lebanon showed that only $65 \%$ of university students brush their teeth two times or more per day (12). Even though the supply and consumption of toothpaste tubes and toothbrushes is less than the optimal level, the quality of toothpaste and toothbrushes available in the Lebanese market are of high standards where products imported are regulated and controlled by LIBNOR.

This study has several limitations which need to be considered when analyzing and interpreting its results. The use of supply of toothpaste tubes and toothbrushes, rather than data of the market sales, to reflect the consumption practices of individuals is one limitation. Although supply can generally predict the number of products consumed by individuals, consumption of toothpaste tubes and toothbrushes is more accurately reflected through the market sales of these products. Yet, our results are to be considered a valid estimation of consumption patterns since the inadequacy of supply will only indicate deficiency in consumption rather than an optimal or over consumption of toothpaste tubes and toothbrushes, given the absence of any local production in Lebanon. Another limitation in our study is the inaccessibility of local or regional studies reporting the supply and consumption of toothpaste tubes and toothbrushes, which need to be taken into consideration when comparing our results.

By using the quantities of toothpaste tubes and toothbrushes imported as proxies for oral hygiene habits, which include brushing with toothpaste, it is assumed that all the imported supplies are being used. It is also assumed that each person uses his/her own toothbrush, and toothpaste and if this is not the case we might be underestimating the number of people

Figure 1 Number of toothpaste tubes (170g) and toothbrushes (20g) supplied per capita in Lebanon per year

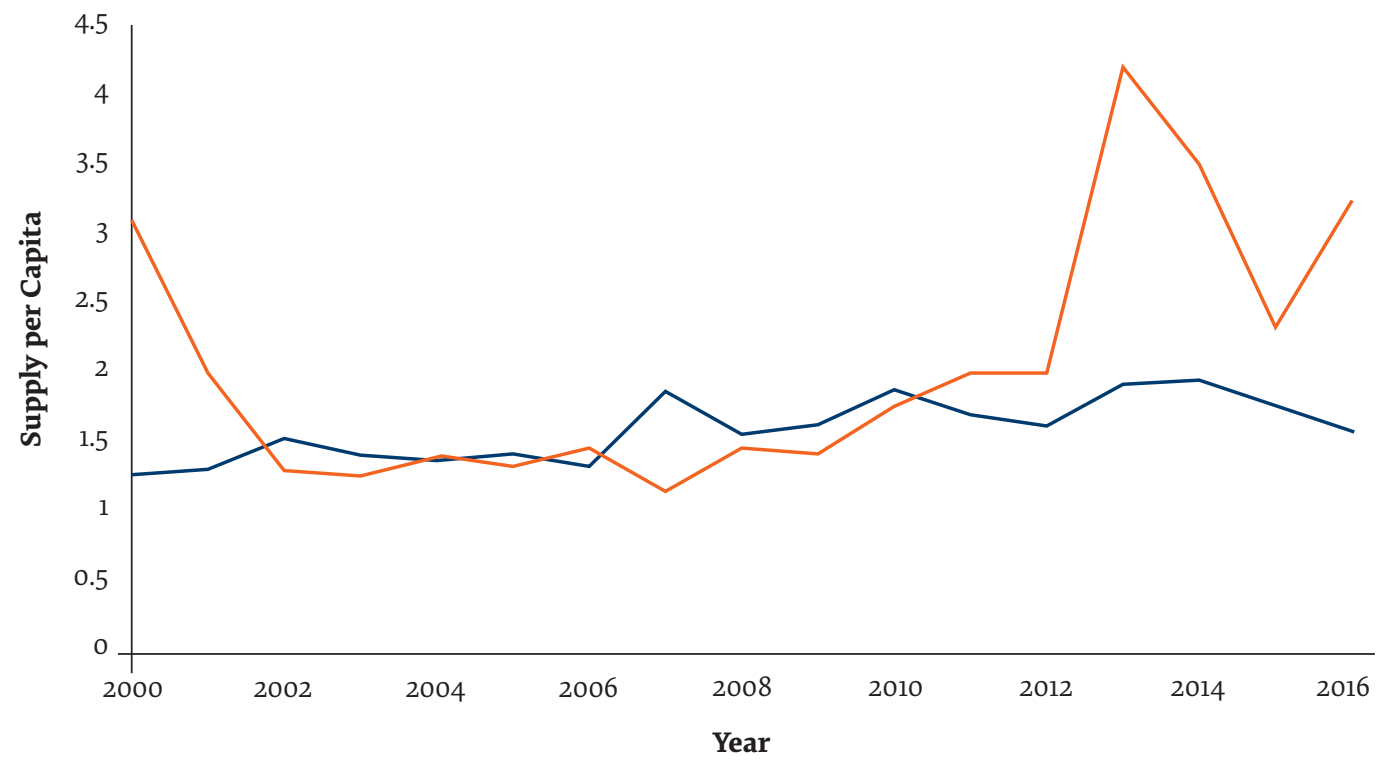

— Number of toothpaste tubes/person _ _ Number of toothbrushes/person 
brushing. People could also be using other kinds of oral hygiene such as mouthwashes, tooth picks etc. In this study we were only looking at oral hygiene measures using toothpaste and toothbrushes. A future study could be conducted using self-reporting via questionnaires.

\section{Conclusion}

Our results reflect yearly consumption patterns of toothpaste and toothbrushes that are below WHO recommendations. This raises the need for several interventions. Given that tooth brushing using fluoridated toothpaste is one of the fundamental oral hygiene practices in preserving oral health (6), there is a need to increase the amount of supplied toothpaste tubes and brushes to provide the adequate recommended yearly amount of these products for every individual. Moreover, promotion programmes targeting mainly children and their parents, focusing on the importance of using a new toothbrush every 3 months and one toothpaste tube every two months, are of paramount importance to comply with WHO recommendations. In addition, such recommendations need to be emphasized by the paediatricians and dentists. Finally, there is a need for further studies that assess the consumption of toothpaste tubes and toothbrushes through evaluating the market sales of such products; this would provide more accurate data about the actual use of toothpaste tubes and toothbrushes by individuals. The latter information can then be correlated with the oral health status of the Lebanese population for better estimates of needs and supply of oral hygiene products. This paper shows the need to sensitize the Lebanese population and government towards the importance of good oral hygiene habits leading to good oral health and its positive effects, and examine the implementation of free preventive dental care policies for people in need.

Funding: None.

Competing interests: None declared.

\section{Tendances de la consommation de brosses à dents et de dentifrices au Liban}

\section{Résumé}

Contexte : La prévalence des caries dentaires est en augmentation, notamment depuis une dizaine d'années. Le brossage des dents deux fois par jour avec un dentifrice fluoré constitue une mesure préventive essentielle. L'Organisation mondiale de la Santé (OMS) recommande l'utilisation annuelle de six tubes de dentifrice de $170 \mathrm{~g}$ chacun et de quatre brosses à dents par individu.

Objectif : Évaluer la consommation individuelle annuelle de tubes de dentifrice et de brosses à dents au Liban en se référant aux quantités commercialisées sur le marché comme mesure indirecte après avoir vérifié si les produits étaient conformes aux normes.

Méthodes : La présente étude reposait sur la réalisation d'une analyse secondaire de données quantitatives relatives au nombre de dentifrices et de brosses à dents commercialisés au Liban entre 2000 et 2016 . La qualité des marques de dentifrices disponibles sur le marché a été évaluée en examinant les directives de l'Institution libanaise de normalisation (LIBNOR) qui régissent les normes de qualité et d'essai pour les produits de santé bucco-dentaire au Liban.

Résultats : La quantité annuelle de tubes de dentifrice par individu a progressivement augmenté, passant de 1,27 à 1,58 tube entre 2000 et 2016. Celle de brosses à dents a connu une fluctuation, passant de 3,1 brosses à dents en 2000 à 3,24 brosses à dents en 2016, année où la tendance a révélé une phase de stagnation suivie par des augmentations puis des diminutions marquées entre 2012 et 2016. Les directives sur la qualité des dentifrices sont régies par le LIBNOR et se conforment aux normes européennes.

Conclusion : La consommation annuelle de tubes de dentifrice et de brosses à dents était en deçà des recommandations de l'OMS. Ces résultats révèlent qu'il existe un besoin de renforcer la promotion de l'importance d'une bonne hygiène buccale, ainsi que de distribuer des tubes de dentifrice et des brosses à dents aux personnes dans le besoin.

$$
\begin{aligned}
& \text { اتجاهات أنحاط استهالك فُرَش ومعاجين الأسنان في لبنان } \\
& \text { منير ضوميط، فدى الصياح } \\
& \text { الخلاصة }
\end{aligned}
$$

معلومات أساسية: ارتفع معدل انتشار تسوس الأسنان خاصة في السنوات العشر الأخيرة. وتنظيف الأسنان بالفرشاة مرتين في اليوم باستخدام

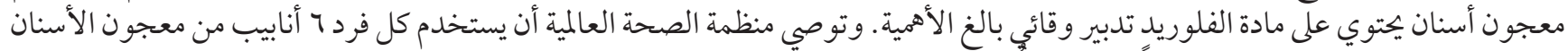

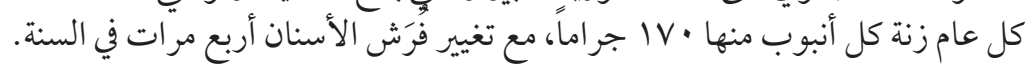

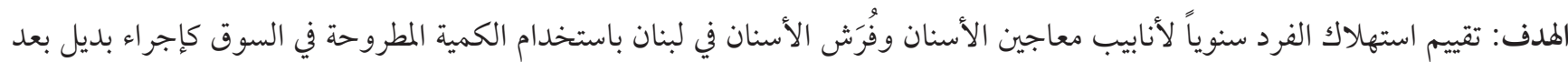

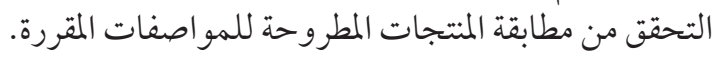

طرق البحث: استندت هذه الدراسة إلى إجراء تحليل ثانوي للبيانات الكمية لكميات معاجين الأسنان وفُرَش الأسنان المطروحة في السوق بين 


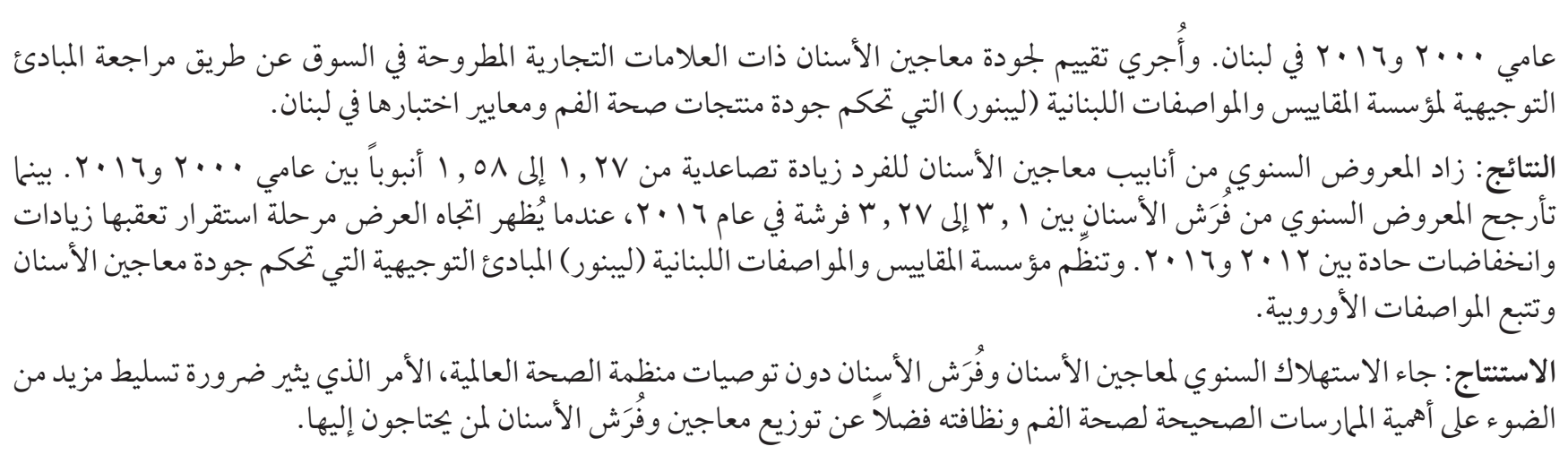

\section{References}

1. World Health Organization. Oral health fact sheet. Geneva: World Health Organization; 2012 [cited 2016 May 17]. http://www. who.int/mediacentre/factsheets/fs318/en/

2. Bagramian RA, Garcia-Godoy F, Volpe AR. The global increase in dental caries. A pending public health crisis. Am J Dent .2009 Feb ;22(1):3-8.

3. Petersen PE, Bourgeois D, Ogawa H, Estupinan-Day S, Ndiaye C. The global burden of oral diseases and risks to oral health. Bull World Health Organ. 2005 Sep ;83(9):661-669.

4. Doumit M, Doughan B. Dental Caries and Fluorosis among Children in Lebanon. J Oral Health Craniofac Sci. $2017 ;$ 2: $001-008$.

5. Sheiham A. Dental caries affects body weight, growth and quality of life in pre-school children. Br Dent J. 2006 Nov;201(10):625626.

6. Petersen PE. The World Oral Health Report 2003: continuous improvement of oral health in the 21st century-the approach of the WHO Global Oral Health Programme. Community Dent Oral Epidemiol. 2003 ;31(s1):3-24.

7. Marinho V, Higgins J, Sheiham A, Logan S. Fluoride toothpastes for preventing dental caries in children and adolescents. Cochrane Database Syst Rev. 2003 Jan ;1(1).

8. Attin T, Hornecker E. Tooth brushing and oral health: how frequently and when should tooth brushing be performed? Oral Health Prev Dent. 2005;3(3):135

9. Community Dent Health. 2016 Jun;33(2):69-99, Fluoride and Oral Health. O’Mullane DM, Baez RJ, Jones S, Lennon MA, Petersen PE, Rugg-Gunn AJ, Whelton H, Whitford GM

10. WHO expert committee on oral health status and fluoride use. Fluorides and oral health. Geneva, World Health Organization; 1994. WHO technical report series 846

11. Doughan B, Kassak K, Bourgeois DM. Oral health behavior of 35-44 year old adults in Lebanon. 2000 (unpublished manuscript).

12. Kassak KM, Dagher R, Doughan B. Oral hygiene and lifestyle correlates among new undergraduate university students in Lebanon. Journal of American College Health. 2001 Jul ;50(1):15-20.

13. Lebanese Customs. 201. Available at: www.customs.gov.lb.

14. Central Administration of Statistics. Lebanon in Figures. Lebanon: Central Administration of Statistics; 2008

15. Lebanese Standards Institution (LIBNOR). NL EN ISO 11609: Dentistry-toothpastes-requirements, test methods and markings. Lebanon: LIBNOR; 2004.

16. American Dental Association, Center for Scientific Information, ADA Science Institute Last Updated: November 7, 2016, www.ada.org/member-center/oral-health-topics/toothbrushes 